\title{
Selection of the Composition with High Glass Forming Ability in Zr-Cu-Ni-Al Bulk Metallic Glasses
}

\author{
Yajuan Sun, ${ }^{1}$ Yumin Li, ${ }^{1}$ and Hongjing Wang ${ }^{2}$ \\ ${ }^{1}$ School of Science, Tianjin Polytechnic University, Tianjin 300387, China \\ ${ }^{2}$ Advanced Technology and Materials Co. Ltd., Beijing 100081, China \\ Correspondence should be addressed to Yajuan Sun; sunyajuan1998@126.com
}

Received 16 February 2014; Accepted 28 April 2014; Published 15 May 2014

Academic Editor: Limei Xu

Copyright (C) 2014 Yajuan Sun et al. This is an open access article distributed under the Creative Commons Attribution License, which permits unrestricted use, distribution, and reproduction in any medium, provided the original work is properly cited.

\begin{abstract}
Three new $\mathrm{Zr}-\mathrm{Cu}-\mathrm{Ni}-\mathrm{Al}$ bulk metallic glasses were developed through appropriate mixing of three binary eutectics $\mathrm{Zr}_{38.2} \mathrm{Cu}_{61.8}, \mathrm{Zr}_{51} \mathrm{Al}_{49}$, and $\mathrm{Zr}_{64} \mathrm{Ni}_{36}$. By suppressing solidification of competing crystalline phases, a new glass forming alloy $\mathrm{Zr}_{51} \mathrm{Cu}_{24.22} \mathrm{Ni}_{14.06} \mathrm{Al}_{10.72}$ with the critical diameter of up to $10 \mathrm{~mm}$ is obtained.
\end{abstract}

\section{Introduction}

Zr-based bulk metallic glasses (BMGs) exhibit many fantastic properties, which are considered as potential structural materials [1-3]. Although some large dimension Zr-based bulk metallic alloys can be obtained as far, such as $\mathrm{Zr}-\mathrm{Ti}-\mathrm{Ni}-\mathrm{Cu}-\mathrm{Be}$ [4], Zr-Cu-Ni-Al [5, 6], Zr-Ti-Cu-Ni-Al [7], Zr-(Ag, Cu)-Al [8], and so on. However, these high GFA Zr-based metallic glasses more or less contain some toxic element (e.g., Be) or noble metals (e.g., Ag, Pd, and Pt). They are still cannot fulfill the requests from commercial applications. The $\mathrm{Zr}$ $\mathrm{Cu}-\mathrm{Ni}$-Al system is a promising candidate for applications due to its nontoxicity and lost cost. Hence, developing the new $\mathrm{Zr}-\mathrm{Cu}-\mathrm{Ni}$-Al glass compositions with high glass forming ability (GFA) is important for the engineering application. At present, various rules have been proposed to design potential glass forming compositions, such as three empirical, but insufficiency and imperfectness still exist [9-11]. Therefore, seeking an efficient guideline to direct this work is still of great challenge.

The investigations by Shen et al. [12] and Lu et al. [13] ever suggested that multicomponent glass forming compositions could be approximately synthesized by the compositions of binary eutectics between the constituent elements through appropriate ratios. Usually, there are two features with these binary eutectics: (1) eutectic temperature is relatively low; (2) the products of the eutectic reactions are linear compounds.
This new method was called appropriate mixing of binary eutectics. As far as now, several Zr-based [12], Ni-based [14], and Cu-based [15] bulk metallic glasses have been successfully developed based on this new approach, which thoroughly demonstrated its usefulness for searching new BMG compositions with high GFA.

In this paper, three new amorphous alloys of the $\mathrm{Zr}-\mathrm{Cu}$ $\mathrm{Ni}$-Al glass forming system were designed, through appropriate mixing of binary eutectic units $\mathrm{Zr}_{38.2} \mathrm{Cu}_{61.8}, \mathrm{Zr}_{51} \mathrm{Al}_{49}$, and $\mathrm{Zr}_{64} \mathrm{Ni}_{36}$. In terms of suppressing the competing crystalline phases in the amorphous matrix which precipitated during melt cooling [16], ratios of these binary eutectic units were adjusted. Therefore, on the condition of without increasing the component but only changing the ratios among these components, three new $\mathrm{Zr}-\mathrm{Cu}-\mathrm{Ni}-\mathrm{Al}$ alloys with high GFA were obtained. One of the three new alloys with a critical diameter of $10 \mathrm{~mm}$ was achieved by only a few times of experiments. Furthermore, GFA of all the three Zr-based amorphous alloys is discussed and investigated through phase selection.

\section{Experiment}

The $\mathrm{Zr}-\mathrm{Cu}-\mathrm{Ni}-\mathrm{Al}$ alloy ingots were prepared by arc melting the mixture of pure $\mathrm{Zr}$ (99.5\%), $\mathrm{Cu}$ (99.9\%), $\mathrm{Ni}$ (99.9\%), and $\mathrm{Al}(99.99 \%)$ metals in a purified argon atmosphere. In order 


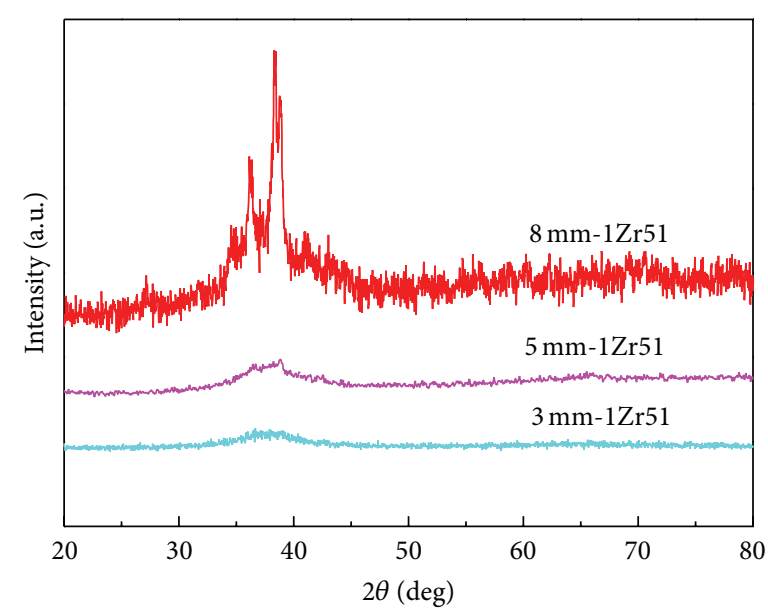

(a) XRD patterns for as-cast $1 Z$ r51 samples with the diameters of $3 \mathrm{~mm}, 5 \mathrm{~mm}$, and $8 \mathrm{~mm}$

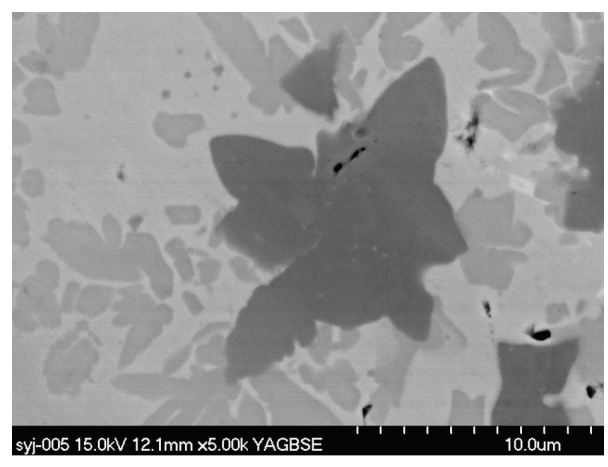

(b) SEM-BSE image for the as-cast 1Zr51 sample with a diameter of $8 \mathrm{~mm}$

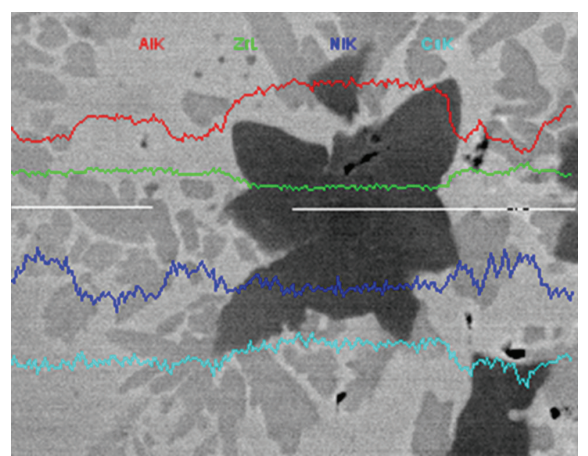

(c) EDS linear analysis showing element distribution in the as-cast 1Zr51 sample with a diameter of $8 \mathrm{~mm}$

FIGURE 1: The XRD and SEM patterns for as-cast $1 \mathrm{Zr} 51$ samples in different diameters.

to ensure the homogeneous composition, master alloys were remelted 4 times, and then they were sucked into the copper mold to form amorphous rod samples in different diameters.

The structure of the as-cast samples was characterized by X-ray diffraction (XRD) with $\mathrm{Cu} K \alpha$ radiation (D/MAX$\mathrm{RB}$ diffractometer). Then scanning electron microscopy (SEM) investigations were performed on the Hitachi S-4700. Thermal analysis was carried out by differential scanning calorimetry (Perkin-Elmer DSC7) and differential thermal analysis (Perkin-Elmer DTA7), both at a heating rate of $0.33 \mathrm{~K} / \mathrm{s}$.

\section{Results and Discussion}

3.1. Formation and Optimization of New $\mathrm{Zr}$-Cu-Ni-Al Glass Alloys. Numerous experimental lines of evidence demonstrated that in $\mathrm{Zr}-\mathrm{Cu}-\mathrm{Ni}-\mathrm{Al}$ amorphous alloy system, the primary crystalline phases are mainly $\mathrm{Zr}-\mathrm{Cu}, \mathrm{Zr}-\mathrm{Ni}$, and $\mathrm{Zr}-\mathrm{Al}$ intermetallic compounds, which are always treated as competing phases with respect to glass phase in this alloy system during cooling melt. Once the driving forces for precipitations of all competing crystalline phases are equivalent, constraints among one another to prevent precipitating might increase, which then leads to a high glass forming ability. Therefore, based on the mixing of binary deep eutectics of $\mathrm{Zr}_{38.2} \mathrm{Cu}_{61.8}, \mathrm{Zr}_{64} \mathrm{Ni}_{36}$, and $\mathrm{Zr}_{51} \mathrm{Al}_{49}$, we choose them as the basic units to design new alloys, which are listed as follows:

$$
\begin{aligned}
C_{a m}= & a\left(\mathrm{Zr}_{38.2} \mathrm{Cu}_{61.8}\right)+b\left(\mathrm{Zr}_{64} \mathrm{Ni}_{36}\right) \\
& +c\left(\mathrm{Zr}_{51} \mathrm{Al}_{49}\right) \quad(a+b+c=1),
\end{aligned}
$$

where $C_{a m}$ is multicomponent alloy composition; $a, b$, and $c$ are the coefficients for the three basic binary eutectic units, respectively, and their sum is the unity. By varying the coefficients of $a, b$, and $c$, the atomic ratios of the alloy components can be changed and then different compositions of $\mathrm{Zr}-\mathrm{Cu}-\mathrm{Ni}$-Al system can be obtained.

Initially, we assigned the coefficients as $a=1 / 3, b=1 / 3$, and $c=1 / 3$ in (1) straightforwardly and then the composition $C_{a m}$ of $\mathrm{Zr}_{51} \mathrm{Cu}_{20.7} \mathrm{Ni}_{12} \mathrm{Al}_{16.3}$ (abbreviated as $1 \mathrm{Zr51}$ ) with a $D_{\max }$ of $3 \mathrm{~mm}$ was followed. The diffuse peak of XRD pattern in Figure 1(a) proves only a single amorphous matrix in this sample. However, for the samples of $5 \mathrm{~mm}$ and $8 \mathrm{~mm}$ in diameters, both XRD pattern (as shown in Figure 1(a)) and SEM-BSE image (as shown in Figure 1(b)) give out some crystalline phases that are dispersed in the amorphous 


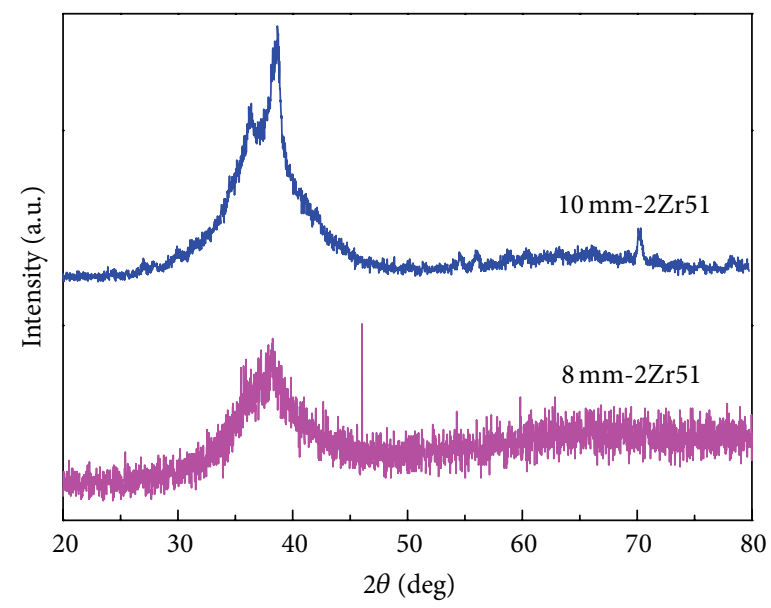

(a) XRD patterns for as-cast 2Zr51 samples with the diameters of $8 \mathrm{~mm}$ and $10 \mathrm{~mm}$

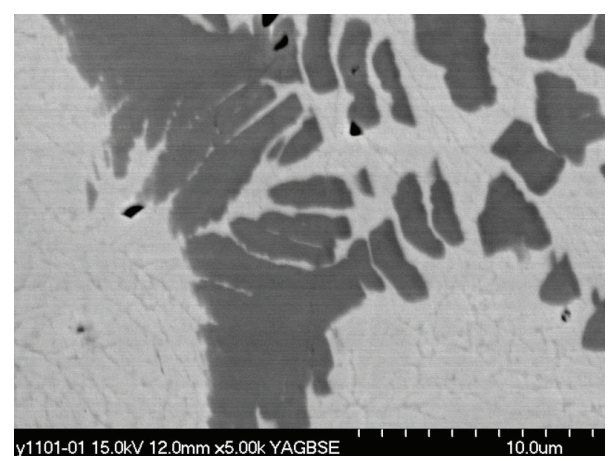

(b) SEM-BSE image for the as-cast 2Zr51 sample with a diameter of $10 \mathrm{~mm}$

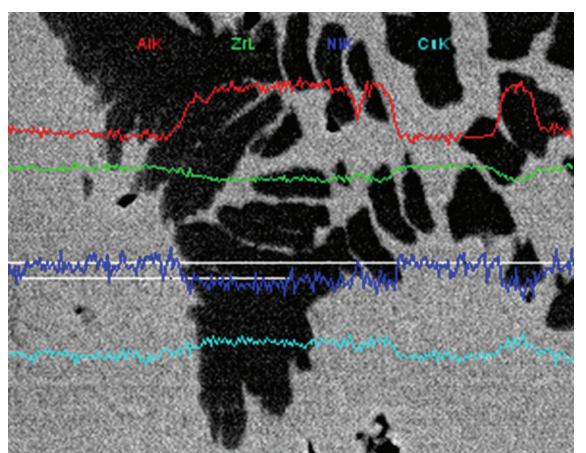

(c) EDS linear analysis showing element distribution in the as-cast $2 \mathrm{Zr} 51$ sample with a diameter of $10 \mathrm{~mm}$

FIGURE 2: The XRD and SEM patterns for as-cast 2Zr51 samples in different diameters.

matrix. Furthermore, $\mathrm{Al}$ is enriched in the primary crystalline phases by SEM-BSE and EDS (as shown in Figure 1(c)) results. Therefore, it can be implied that the precipitation of enriched $\mathrm{Al}$ phases is the main obstacle to further enhance GFA of this alloy $1 \mathrm{Zr} 51$ (i.e., content of aluminum element is relatively excessive, compared to other elements).

As a result, in order to improve the GFA of this alloy system without increasing the component species, we tried to decrease the coefficients for $\mathrm{Zr}_{51} \mathrm{Al}_{49}$ eutectic units in (1) to depress the precipitation of enriched $\mathrm{Al}$ phases. Thus, on the base of the initial alloy $1 \mathrm{Zr} 51$, the coefficient for $\mathrm{Zr}_{51} \mathrm{Al}_{49}$ eutectic units was decreased to $c=2 / 8$, but coefficients for $\mathrm{Zr}_{64} \mathrm{Ni}_{36}$ and $\mathrm{Zr}_{38.2} \mathrm{Cu}_{61.8}$ eutectic units were increased to $a=b=3 / 8$. And this led to the new composition of $\mathrm{Zr}_{51} \mathrm{Cu}_{23.2} 5 \mathrm{Ni}_{13.5} \mathrm{Al}_{12.25}$ (abbreviated as 2Zr51) accompanied with an amorphous rod sample of $8 \mathrm{~mm}$ in diameter. Also the XRD patterns for this as-cast 2Zr51 rod samples in different diameters are shown in Figure 2(a). It can be clearly seen that the $8-\mathrm{mm} 2 \mathrm{Zr} 51$ is essentially amorphous, evidenced by the unique broad diffuse halo in this XRD. This means GFA of this alloy system has been improved through turning the coefficients of $a, b$, and $c$. However, when we increased the size of the $2 \mathrm{Zr} 51$ rod sample to a diameter of $10 \mathrm{~mm}$, as the
XRD pattern in Figure 2(a), SEM-BSE, and EDS images in Figures 2(b) and 2(c) results indicated, some enriched $\mathrm{Al}$ phases precipitated during cooling the melt.

From the above discussion, to suppress precipitation of enriched $\mathrm{Al}$ phases and get better glass former, we can decrease the coefficient of $c$ in (1) to $c=3.5 / 16$, while $a$ and $b$ increase to $a=b=6.25 / 16$. As a result, it followed another composition of $\mathrm{Zr}_{51} \mathrm{Cu}_{24.22} \mathrm{Ni}_{14.06} \mathrm{Al}_{10.72}$ (abbreviated as $3 \mathrm{Zr} 51$ ), and we finally obtained an amorphous rod sample of $10 \mathrm{~mm}$ in diameter. The XRD pattern in Figure 3(a) shows only a single diffuse halo that displays a homogeneous matrix without any crystalline phases. Further, SEM-BSE image in Figure 3(b) indicates that there are no crystalline phases. All of these demonstrated that the $3 \mathrm{Zr} 51$ rod sample with the diameter of $10 \mathrm{~mm}$ is in full amorphous state. However, when increasing the size of the $3 \mathrm{Zr} 51$ alloy to $12 \mathrm{~mm}$ in diameter, some crystalline phases precipitate. The sharp peaks in XRD pattern are shown in Figure 3(a). It is noted that potential alloy compositions with even better GFA could be difficultly found by adjustment of coefficients further in (1).

The alloy compositions, abbreviations, adjustment of mixing constants, and critical sizes $D_{\max }$ are summarized in Table 1 . 


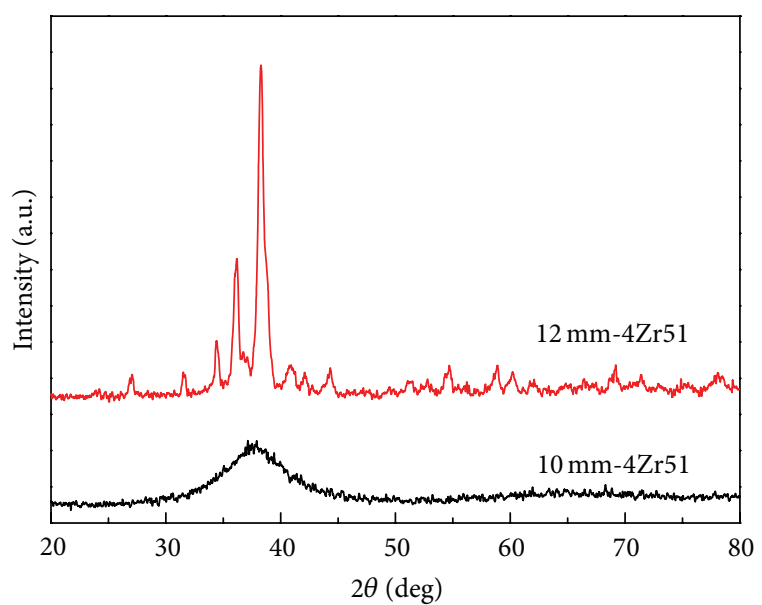

(a)

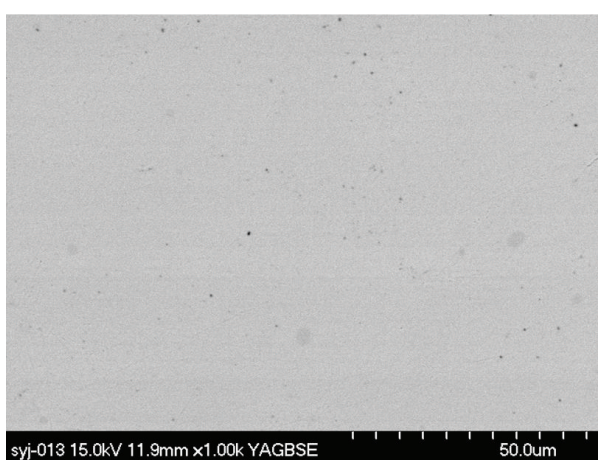

(b)

FIGURE 3: The XRD (a) and SEM-BSE (b) patterns for as-cast 3Zr51 sample with the diameter of $10 \mathrm{~mm}$.

TABLE 1: The new alloy compositions, abbreviations, adjustment of mixing constants, critical sizes $D_{\max }$, and thermal parameters for the Zr-Cu-Ni-Al alloys.

\begin{tabular}{|c|c|c|c|c|c|c|}
\hline BMGs compositions (abbreviation) & Mixing coefficients $a, b$, and $c$ & $D_{\max }$ & $T_{g}$ & $T_{x}$ & $T_{m}$ & $T_{g} / T_{m}$ \\
\hline $\mathrm{Zr}_{51} \mathrm{Cu}_{20.7} \mathrm{Ni}_{12} \mathrm{Al}_{16.3}(\mathbf{1 Z r 5 1})$ & $a=1 / 3, b=1 / 3, c=1 / 3$ & $<5 \mathrm{~mm}$ & 727 & 817 & 1049 & 0.6930 \\
\hline $\mathrm{Zr}_{51} \mathrm{Cu}_{23.2} 5 \mathrm{Ni}_{13.5} \mathrm{Al}_{12.25}$ (2Zrr51) & $a=3 / 8, b=3 / 8, c=2 / 8$ & $8 \mathrm{~mm}$ & 726 & 806 & 1047 & 0.6934 \\
\hline $\mathrm{Zr}_{51} \mathrm{Cu}_{24.22} \mathrm{Ni}_{14.06} \mathrm{Al}_{10.72}(\mathbf{Z Z r 5 1})$ & $a=6.25 / 16, b=6.25 / 16, c=3.5 / 16$ & $10 \mathrm{~mm}$ & 725 & 781 & 1041 & 0.6964 \\
\hline
\end{tabular}

TABLE 2: The critical sizes $\left(D_{\max }\right)$ in our lab for previously reported Zr-based BMGs.

\begin{tabular}{llc}
\hline $\begin{array}{l}\text { Amorphous alloy systems with the corresponding } \\
\text { abbreviation }\end{array}$ & $D_{\max }$ \\
\hline $\mathrm{Zr}_{65} \mathrm{Cu}_{17.5} \mathrm{Ni}_{10} \mathrm{Al}_{7.5}$ & $(\mathrm{Zr} 65)[5]$ & $<6 \mathrm{~mm}$ \\
$\mathrm{Zr}_{55} \mathrm{Cu}_{30} \mathrm{Ni}_{5} \mathrm{Al}_{10}$ & $(\mathrm{Zr} 55)[6]$ & $<10 \mathrm{~mm}$ \\
$\mathrm{Zr}_{51} \mathrm{Cu}_{24.22} \mathrm{Ni}_{14.06} \mathrm{Al}_{10.72}$ & $(3 \mathrm{Zr} 51)[$ present] & $10 \mathrm{~mm}$ \\
\hline
\end{tabular}

For further comparisons, some other previously reported Zr-based amorphous alloys with high GFA were also fabricated under the same experimental condition in our lab. Table 2 lists their critical sizes $\left(D_{\max }\right)$ in our lab. The XRD patterns are shown in Figure 4. It indicates that among the $\mathrm{Zr}-\mathrm{Cu}-\mathrm{Ni}-\mathrm{Al}$ quaternary alloy systems, $3 \mathrm{Zr} 51$ owns the largest size. It is believed that a further improvement of the prepared methods causes the formation of $3 \mathrm{Zr} 51$ bulk amorphous alloy with a larger diameter.

3.2. Thermal Analysis of New $\mathrm{Zr}$-Cu-Ni-Al Glass Alloys. DSC and DTA curves for the amorphous alloys of the three different $\mathrm{Zr}-\mathrm{Cu}-\mathrm{Ni}-\mathrm{Al}$ alloys are shown in Figure 5. Corresponding thermal parameters are listed in Table 1, including the glass transition temperature $T_{g}$, onset crystallization temperature $T_{x}$, melting temperature $T_{m}$, and reduced glass transition temperature $T_{r g}=T_{g} / T_{m}$. As can be seen in Figure 5(a), the three alloys show a distinct glass transition, a significant supercooled liquid region, and a clear endothermic event, illustrating characteristics of BMGs. So as far as now, the

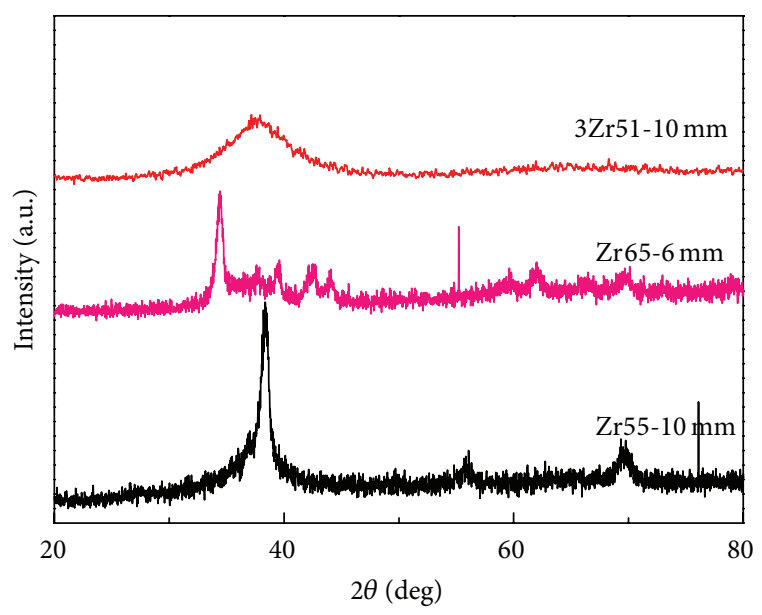

FIGURE 4: The XRD patterns for previously reported as-cast Zrbased amorphous alloy samples in different diameters.

reduced glass transition temperature $T_{r g}$ and the critical size $D_{\max }$ of the samples are the most powerful criteria to characterize the glass forming ability. Distinct correlation is found between GFA and the values of $T_{r g}$ for our newly developed alloys. Among the three new alloys, the best glass forming alloy $3 \mathrm{Zr} 51$ processes highest value of $T_{r g}$.

3.3. Glass Forming Ability of New $\mathrm{Zr}$-Cu-Ni-Al Glass Alloys. As we discussed formerly, eutectic compositions are the best candidates for glass formation. Another thing we should 


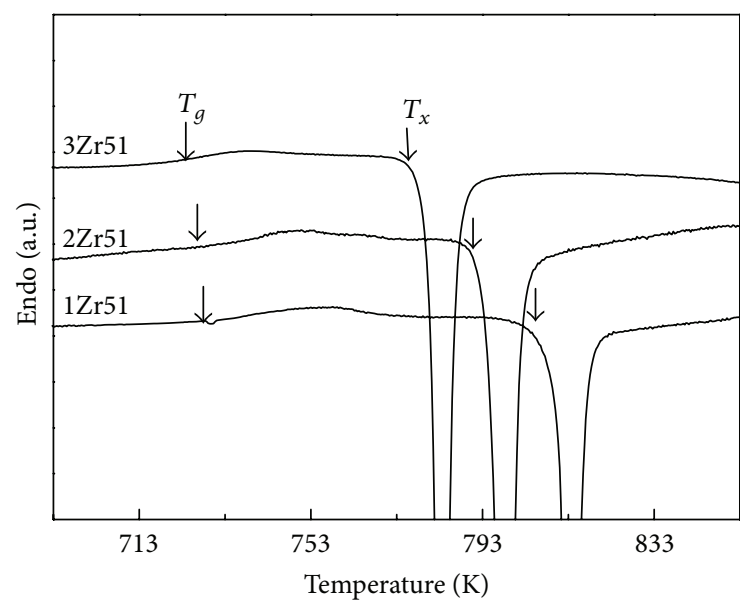

(a)

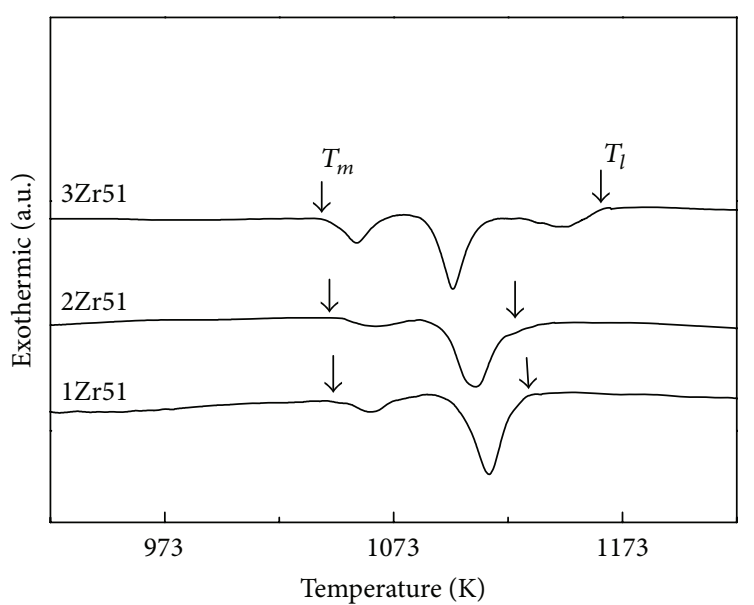

(b)

FIGURE 5: The DSC (a) and DTA (b) curves for as-cast 1Zr51, 2Zr51, and 3Zr51 BMG samples.

mention again is that in our mixing of binary eutectics method, the eutectic reaction products are both linear compounds. As Shen et al. [12] ever suggested if the chemical affinity between the eutectic atomic pairs can be balanced to a certain degree, the atomic rearrangement to form crystalline phases during melt cooling is rather difficult, which structurally supports improving glass forming ability. That is why we preferred to choose $\mathrm{Zr}_{38.2} \mathrm{Cu}_{61.8}, \mathrm{Zr}_{64} \mathrm{Ni}_{36}$, and $\mathrm{Zr}_{51} \mathrm{Al}_{49}$ as the three preliminary units. We also assumed that such a balance can be achieved by proportionally mixing the corresponding binary eutectic compositions.

As a matter of fact, the physical meaning of this method is ambiguous, but lots of compositions obtained through our new method and reported in the literatures demonstrate that the efficiency of this method is astonishing. The compositions obtained through proportionally combining the binary eutectics are very close to those reported in the literatures [17]. However, it must be noted that the binary eutectics should be involved in reactions with compound products and the ratios between the eutectics should be varied according to experiments.

On the other hand, during cooling the alloy melt phase selection is inevitably avoided. Either crystalline phases or metallic glass will be obtained. However, as Ma et al. [18] pointed out if treating glass as another competing phase, glass formation could be interpreted as the complete suppression of crystal growth by glass phase. So once the crystalline phase's precipitation is depressed, GFA will be naturally improved.

Thus, according to the above concept, we designed the first composition $\mathrm{Zr}_{51} \mathrm{Cu}_{20.7} \mathrm{Ni}_{12} \mathrm{Al}_{16.3}$ (1Zr51) by assigning $a=b=c=1 / 3$ as described in (1). In fact, this assignment is straightforwardly obtained and we succeeded in obtaining a $3 \mathrm{~mm}$ as-cast rod sample. Its efficiency can be proved by experiments. However, some enriched $\mathrm{Al}$ crystalline phases appear in a larger sample of $5 \mathrm{~mm}$ and $8 \mathrm{~mm}$ in diameter. $\mathrm{Lu}$ et al. [19] ever suggested that in order to obtain the better glass forming composition, primary precipitation in the melt should be bypassed no matter what crystalline phases they are. One of the effective approaches is to suppress the precipitation of crystalline phases through phase competition. Here we just choose to vary the ratios of the three eutectic units rather than introduce another component. Consequently, the second composition $\mathrm{Zr}_{51} \mathrm{Cu}_{23.2} 5 \mathrm{Ni}_{13.5} \mathrm{Al}_{12.25}$ (2Zr51) was obtained when $a=b=3 / 8$, but $c=2 / 8$. And correspondingly we obtained a larger as-cast amorphous rod with a diameter of $8 \mathrm{~mm}$. But a larger $10 \mathrm{~mm}$ rod sample with some enriched $\mathrm{Al}$ crystalline phases once reminded us that if we want to improve the GFA of this alloy system, adjusting the ratios must be tried another time. By varying the ratios of the three units to $a=b=6.25 / 16$ while $c=3.5 / 16$, the third alloy $\mathrm{Zr}_{51} \mathrm{Cu}_{24.22} \mathrm{Ni}_{14.06} \mathrm{Al}_{10.72}$ (3Zr51) finally followed which can be cast into an amorphous rod up to $10 \mathrm{~mm}$ in diameter. It is one of the best glass formers in the $\mathrm{Zr}-\mathrm{Cu}-\mathrm{Ni}-\mathrm{Al}$ alloy system.

Ma et al. [18] ever suggested a microstructure-based method to pinpoint the best glass forming composition. From lots of their work, pinpointing the composition was largely based on the microstructure evolution. Here the concept is the same. The difference is that their work largely relied on the phase diagram. But we depressed the precipitation of competing phases only through varying the ratios of the three eutectic units. On the other hand, during this variation, chemical affinities of the four components gradually got balanced. The alloy compositions with high GFA were obtained by varying three eutectic units coefficients $a, b$, and $c$.

Furthermore, we analyzed the reason for the increase in GFA of $2 Z r 51$ and $3 Z$ r51 compared with $1 Z$ r51. As can be seen from Table $1, T_{m}$ decreases with the composition. High $T_{r g}$ for $2 \mathrm{Zr} 51$ and $3 \mathrm{Zr} 51$ indicates that the alloy is close to deep eutectic and, therefore, exhibits better GFA. Especially, 3Zr51 has a rather low $T_{m}$. The decrease in melting point indicates that the liquid phase is stabilized with respect to competing crystalline phases. Also knowing from physical metallurgy, we understand that viscosities of eutectic alloys are usually higher than other off-eutectics, which dynamically supported the best glass forming composition of them. As a result, $2 \mathrm{Zr} 51$ 
and 3Zr51 show high GFA compared with 1Zr51, because the alloy compositions are closer to deep eutectic by varying ratios of the three binary units.

\section{Conclusion}

We utilized an efficient method of proportional mixing of binary eutectics to successfully design three new $\mathrm{Zr}-\mathrm{Cu}$ $\mathrm{Ni}-\mathrm{Al}$ quaternary amorphous alloy compositions. Firstly we obtained a composition $\mathrm{Zr}_{51} \mathrm{Cu}_{20.7} \mathrm{Ni}_{12} \mathrm{Al}_{16.3}$ (1Zr51) with a critical maximal size of $3 \mathrm{~mm}$ in diameter. Then, through varying the atomic ratios in this composition, a full amorphous $\mathrm{Zr}_{51} \mathrm{Cu}_{24.22} \mathrm{Ni}_{14.06} \mathrm{Al}_{10.72}$ (3Zr51) rod sample with a critical maximal diameter of $10 \mathrm{~mm}$ was achieved. High GFA of the three alloys resulted from depressing these precipitated phases by varying ratios of the three binary units.

\section{Conflict of Interests}

The authors declare that there is no conflict of interests regarding the publication of this paper.

\section{Acknowledgments}

The research was supported by the Tianjin Research Program of Application Foundation and Advanced Technology (no. 13JCQNJC02900).

\section{References}

[1] W. L. Johnson, "Bulk glass-forming metallic alloys: science and technology," MRS Bulletin, vol. 24, no. 10, pp. 42-56, 1999.

[2] W. H. Wang, C. Dong, and C. H. Shek, "Bulk metallic glasses," Materials Science and Engineering: Reports, vol. 44, no. 2-3, pp. 45-89, 2004.

[3] W. Chen, Z. Liu, and J. Schroers, "Joining of bulk metallic glasses in air," Acta Materialia, vol. 62, pp. 49-57, 2014.

[4] A. Peker and W. L. Johnson, "A highly processable metallic glass: $\mathrm{Zr}_{41.2} \mathrm{Ti}_{13.8} \mathrm{Cu}_{12.5} \mathrm{Ni}_{10.0} \mathrm{Be}_{22.5}$," Applied Physics Letters, vol. 63, Article ID 2342, 1993.

[5] A. Inoue, T. Zhang, N. Nishiyama, K. Ohba, and T. Masumoto, "Preparation of $16 \mathrm{~mm}$ diameter rod of amorphous $\mathrm{Zr}_{65} \mathrm{Al}_{7.5} \mathrm{Ni}_{10} \mathrm{Cu}_{17.5}$ alloy," Materials Transactions, JIM, vol. 34, no. 12, pp. 1234-1237, 1993.

[6] A. Inoue and T. Zhang, "Fabrication of bulk glassy $\mathrm{Zr}_{55} \mathrm{Al}_{10} \mathrm{Ni}_{5} \mathrm{Cu}_{30}$ alloy of $30 \mathrm{~mm}$ in diameter by a suction casting method," Materials Transactions, JIM, vol. 37, no. 2, pp. 185-187, 1996.

[7] L. Q. Xing, P. Ochin, M. Harmelin, F. Faudot, J. Bigot, and J. P. Chevalier, "Cast bulk $\mathrm{Zr}-\mathrm{Ti}-\mathrm{Cu}-\mathrm{Ni}$ amorphous alloys," Materials Science and Engineering: A, vol. 220, no. 1-2, pp. 155$161,1996$.

[8] Q. K. Jiang, X. D. Wang, X. P. Nie et al., " $\mathrm{Zr}-(\mathrm{Cu}, \mathrm{Ag})$ - Al bulk metallic glasses," Acta Materialia, vol. 56, no. 8, pp. 1785-1796, 2008.

[9] A. Inoue, J. Saida, M. Matsushita, and T. Sakurai, "Formation of an icosahedral quasicrystalline phase in $\mathrm{Zr}_{65} \mathrm{Al}_{7.5} \mathrm{Ni}_{10} \mathrm{M}_{17.5}$ $(\mathrm{M}=\mathrm{Pd}$, Au or Pt) alloys," Materials Transactions, JIM, vol. 41, no. 2, pp. 362-365, 2000.
[10] A. Inoue, "Stabilization of metallic supercooled liquid and bulk amorphous alloys," Acta Materialia, vol. 48, no. 1, pp. 279-306, 2000.

[11] J. F. Loffler, "Bulk metallic glasses," Intermetallics, vol. 11, no. 6, pp. 529-540, 2003.

[12] J. Shen, J. Zou, L. Ye et al., "Glass-forming ability and thermal stability of a new bulk metallic glass in the quaternary $\mathrm{Zr}-\mathrm{Cu}-$ Ni-Al system," Journal of Non-Crystalline Solids, vol. 351, no. 30-32, pp. 2519-2523, 2005.

[13] Z. P. Lu, J. Shen, D. W. Xing, J. F. Sun, and C. T. Liu, "Binary eutectic clusters and glass formation in ideal glass-forming liquids," Applied Physics Letters, vol. 89, Article ID 071910, 2006.

[14] W. Z. Liang, Glass-forming ability and fracture behavior of NiTiZrAlCuSi alloys [Ph.D. dissertation], Harbin Institute of Technology, Harbin, China, 2003.

[15] Y. J. Yang, D. W. Xing, C. P. Li, S. D. Wei, J. K. Sun, and Q. K. Shen, "A new way of designing bulk metallic glasses in $\mathrm{Cu}-\mathrm{Ti}-$ Zr-Ni system," Materials Science and Engineering: A, vol. 448, no. 1-2, pp. 15-19, 2007.

[16] D. Wang, H. Tan, and Y. Li, "Multiple maxima of GFA in three adjacent eutectics in $\mathrm{Zr}-\mathrm{Cu}-\mathrm{Al}$ alloy system-a metallographic way to pinpoint the best glass forming alloys," Acta Materialia, vol. 53, no. 10, pp. 2969-2979, 2005.

[17] Y. J. Sun, D. D. Qu, Y. J. Huang et al., " $\mathrm{Zr}-\mathrm{Cu}-\mathrm{Ni}-\mathrm{Al}$ bulk metallic glasses with superhigh glass-forming ability," Acta Materialia, vol. 57, no. 4, pp. 1290-1299, 2009.

[18] D. Ma, H. Tan, D. Wang, Y. Li, and E. Ma, "Strategy for pinpointing the best glass-forming alloys," Applied Physics Letters, vol. 86, Article ID 191906, 2005.

[19] Z. P. Lu, D. Ma, C. T. Liu, and Y. A. Chang, "Competitive formation of glasses and glass-matrix composites," Intermetallics, vol. 15, no. 3, pp. 253-259, 2007. 

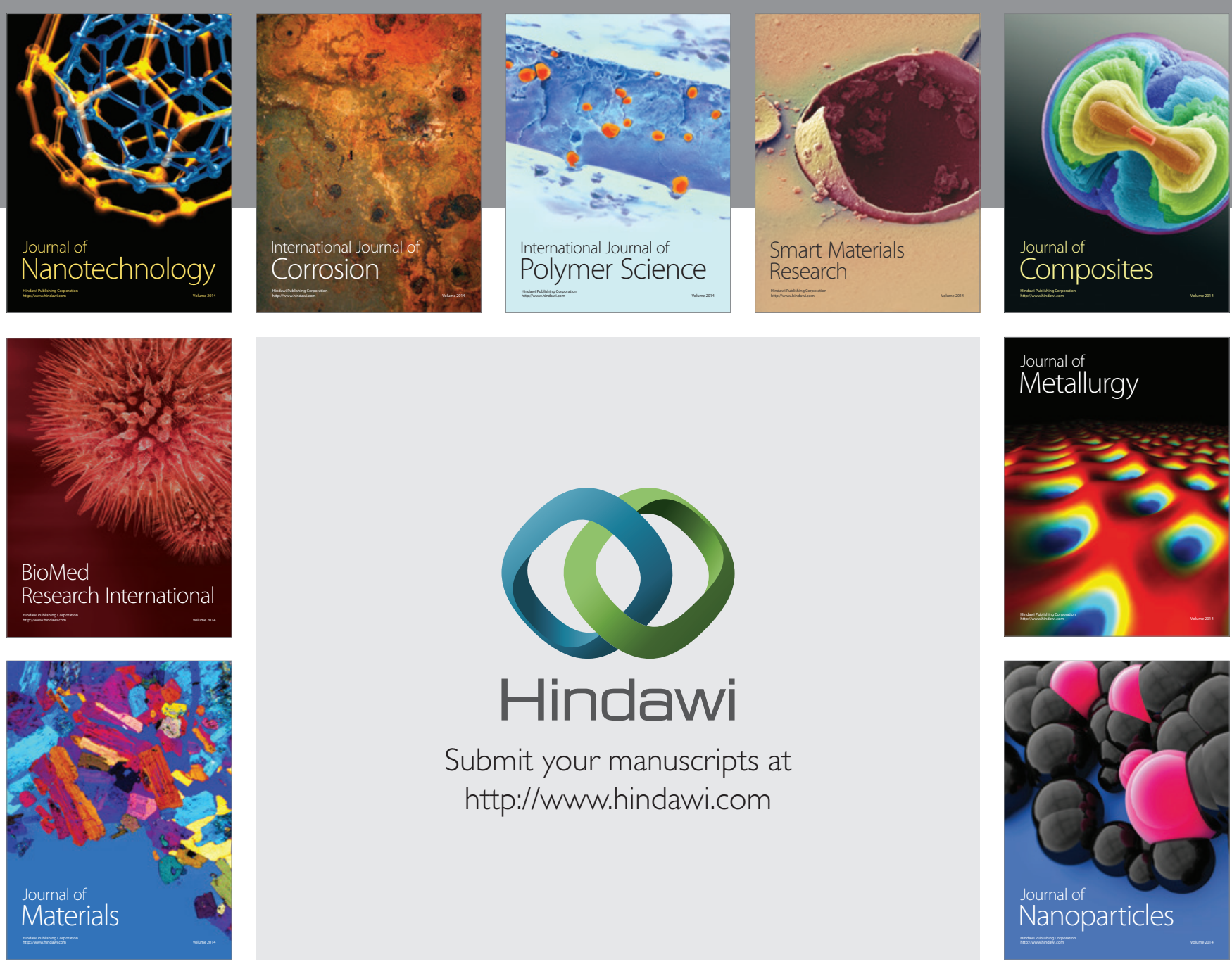

Submit your manuscripts at http://www.hindawi.com
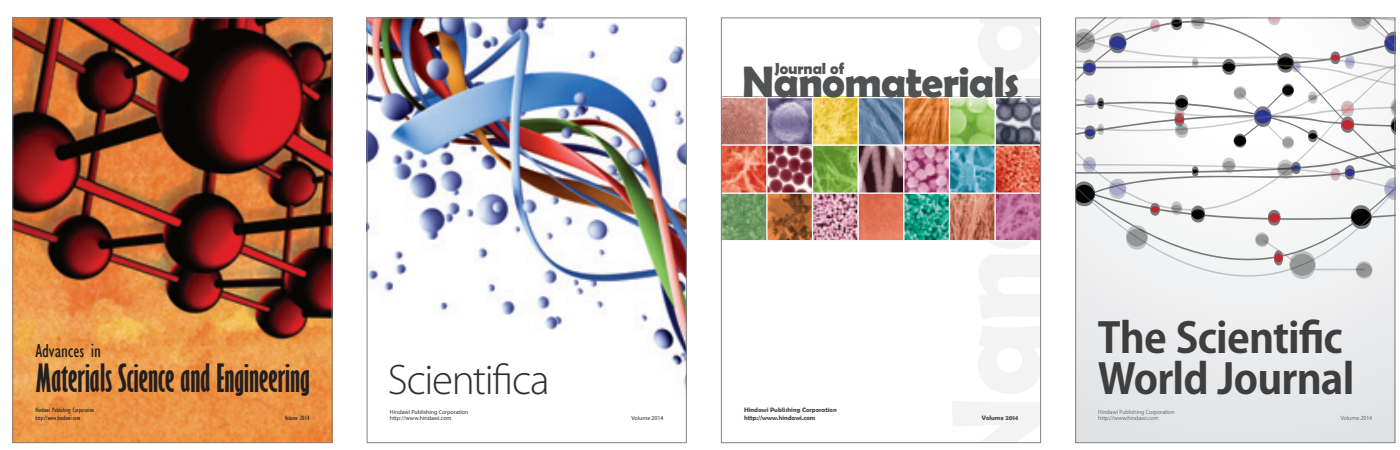

\section{The Scientific World Journal}
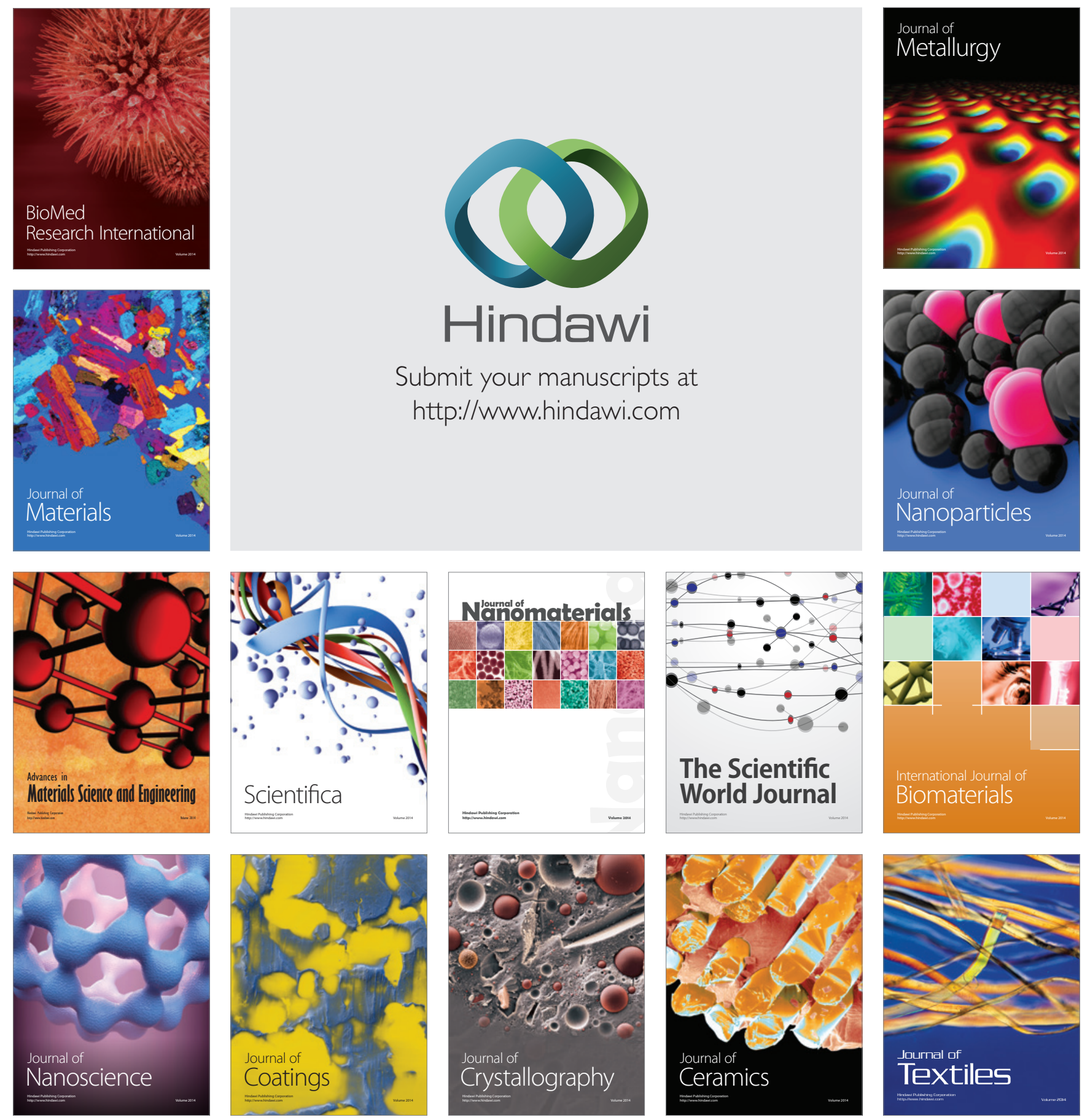